\title{
The Role of Libraries in Knowledge Management
}

\author{
Doris U. Aghoghovwia, \\ M.Sc (Library And Information Science) Senior Librarian Delta State College Of Physical Education, Mosogar \\ Gms
}

\begin{abstract}
The development of knowledge management in recent years has become a great concern for librarians and libraries. This paper willreview the development of knowledge management.It will also examine the role of librarians/libraries in knowledge management and recommends that librarians/libraries in the digital age should be in change of knowledge management in their respective organizations in order to leverage the intellectual assets and to facilitate knowledge creation.
\end{abstract}

\section{Introduction}

The concept knowledge management began and popularized in the business world during the last decade of the 20th century. It was the business world that first recognized the importance of knowledge in the "global economy" of the "knowledge age" In the new knowledge economy, the possession of relevant and strategic knowledge and its unceasing renewal enables business in gain competitive advantage. The applications of knowledge management have now spread to other organizations including government agencies, research and development departments, universities and others.

The management of information has long been regarded as the domainof librarians and libraries. Librarians and information professionals are trained to be experts in information searching, selecting, acquiring, organizing, preserving, repackaging, disseminating, and serving. However, professionals in information technology and systems have also taken information management as their domain because of the recent advances in information technology and systems which drives and underpin information management.One of the clearest evidence of this is that the positions of "Chief Information Officers" (CIO) in many organizations are generally held by information technologist instead of librarians. In fact, most of the work of CIOs has to do with developing and managing the information technology infrastructure and systems, not managing of information perse.

With the growing interest in knowledge management, many questions have been raised in the minds librarians concerning the difference between information and management and knowledge management; who should be in change of information and knowledge management; would librarians and information professionals with appropriate education training in library and information science be most suitable for the position of "Chief knowledge officer" (CKO) in their organizations; and what libraries can do in implementing knowledge management.

\section{Knowledge Management In Libraries}

Just as the business world is changing in the new knowledge economy and digital age, libraries of all types are undergoing drastic changes also. The new role of libraries in the 21 st century needs to be as a learning and knowledge center for their users as well as the intellectual commons for their respective communities where, to borrow the phrase from the keystone principles "people and ideas interact in both the real and virtual environment to expands learning and facilitate the creation of new knowledge". As a learning organization, libraries should provide a strong leadership in knowledge management. Unlike those business organization whose aim for managing knowledge is for competitive advantage instead of competition, internal use only, and little sharing of knowledge with others, the most important mission, libraries should aim their knowledge management goal high.

Below are examples for what libraries can do to improve their knowledge management in all of the key areas of library services.

\section{- Knowledge Resources Management}

Due to exponential growth in human knowledge in a variety of formats, there is need for libraries to develop their resources access and sharing strategies from printed to electronic and digital resources in concert with their mission and charges. Restricted by inadequate funding, technology, staff and spacelibraries must carefully analysis the needs of their users and seek to develop co-operative acquisition plans to meet these needs (Lee, 
2005). The changing concept from "ownership" to "access" and from "just in case" to just on time"should be the goal of a sound resources development strategy.

An integrated online public access catalogue (OPAC) with both internal and external resources as well as printed ad other formats of knowledge should be developed and maintained. Useful websites and knowledge sources should be regularly searched and selected from the internet and included in OPACS by hard links. A system for the reviewing and updating these resources should be performed.

Libraries should also develop means of capturing all tacit knowledge that is useful to their users, their organizations, and to the internal operation of libraries. The website of each library should serve as a portal for all sources relevant knowledge and information of various types. Universities and research organizations which are knowledge reservoirs should be inventored, archived, indexed, frequently updated and made accessible in digital form.

In addition, libraries are encouraged to use Dublin Core Metadata and co-operative online resources catalogue (CORC) that has the ability to capture web information by co-operative efforts instead of depending upon the traditional, time honored methods of cataloguing and classification which are inadequate to deal with the almost infinite amount of digital information in large electronic databases and on the internet.

\section{- Resources sharing and networking}

Libraries have had a long tradition of resources sharing and networking. These have been greatly expanded by the rapid development of computers, telecommunication, networking and digital technologies since the 1960s. In the U.S, it is very common for libraries to be a member of several consortia at the same time for various types of co-operative work and resources shunning. The best examples of these are the online computer library center (OCLC) and Ohio Link (Ohio library and information Network).

The CORE Project of OCLC should be especially useful for libraries to co-operatively capture digital resources of all types, describe them in a standard format, and make them easily searchable by users.

The success of the above listed examples in resources sharing and networking largely depend upon the full cooperation and participation of all members libraries without selfishness (Lee, 2005)

\section{- Information technology development}

Lee (2005) pointed out that "to facilitate the implementation of knowledge management a welldesigned and operational knowledge management system should be in place. He further stated that, latest information technology should be used as an enabler. In this regard, the chief librarian, the library director, etc should consider him/herself as the chief knowledge officer of the entire organization and work together with CIO, heads of the planning department, the computer and technology center, the human resources management department, the finance department, etcto design and develop such a knowledge management system should be built on existing computer and information technology infrastructures, including upgraded intranet, extranet, internet, and available software programmes to facilitate the capture, analysis, organization, storage, and sharing of internal and external information resources for effective knowledge exchange among users, resource persons, publishers, government agencies, business and industries and other organizations via multiple channels and layers. It was observed by Hsinchun Chen that "since the mid 1990s, the popularity of search engines and advances in web spidering, indexing, and link analysis have 12 knowledge transformed system IR systems into newer and more powerful search tools for content on the internet.

\section{Users Services}

The utmost goal of knowledge management is to provide users with different various quality services in order to improve the communication, use and creation of knowledge. (Lee, 2005). As much as possible these services should be tailed toward the interest and need of users. Information about each user can be obtained by analyzing the records of users' registration, surveys, circulation and inter library loan, frequently asked reference question, and the use of e-journal and digital resources, etc. User satisfaction and needs should be collected through periodicuser's surveys. The findings should be used for the planning and redesign of library services. It is essential that users, privacy should be protected. Some of the manuals services such as "new publication alert and selective dissemination of information which libraries have been providing, can now be done automatically by employing the push technology with great efficiency and convenience.Each library user can also set up his/her virtual MY LIBRARY" enabled by library systems and networks for collecting and organizing resources for personal use and to stay informed of new resources provided by the library (Cohen, 204.et al) 


\section{Human Resources Management}

A great deal of expert knowledge is possessed by library staff and users, whether in and outside the library. Such knowledge expertise are abundant in universities and research communities and should be inventoried, indexed, updated regularly and be made searchable and accessible through electronics databases created and maintained by libraries. Lee, (2005) opined 'That' "the knowledge and accumulated experiences of library staff member's form the intellectual assets of any library and should be valued and shared". An organizational a culture for sharing of knowledge and expertise should be established with appropriate rewards and incentives. Those staff members who share their tacit knowledge and experiences through writing, publishing, lecturing, tutoring, or mentoring should be appropriately recognized and rewarded. An organizational culture which emphasizes co-operation, sharing and innovation can only by established by strong leadership and commitment from the library director and a shared vision by the library staff. As a learning organization, libraries should allocate annual fund to provide continuing education and staff training to all staff members. Knowledge must be renewed and expanded to prevent it from becoming stagnant.

According to Lee (2005), "Libraries should also encourage the transfer of knowledge and experiences from experienced staff to new staff members. "A mentoring systems should be in place to help new comers to learn from experienced library staff. Informal seminars and brow bag sessions where staff can interact and exchange "lessons learnt", "best practices", and other specific experience and knowledge should be scheduled at regular intervals and at convenient time. Special interest groups and chart rooms can be created through intranet. Since many valuable experiences have been accumulated over time, libraries should pay attention to favourable working conditions and environments, which will contribute to better staff retention.

\section{Conclusion:}

In the business world where knowledge management is seen as means for organisations to gain competitive advantage over their competitors, to add value to their product and win greater satisfaction from their customers, the libraries/librarians should learned a lesson from the business world by putting together their long and rich experiences as well as their skills of librarianship to manage knowledge. For any library to succeed in implementing knowledge management, will require a strong leadership and vision from the top administration which can influence the organisations is knowledge sharing efforts in a positive ways. As librarians are in the knowledge age of the $21^{\text {st }}$ century, we should not take a back seat in the development of knowledge management instead, librarians should work together with information technology professionals and others to develop the appropriate knowledge management system since information technology and systems can provide effective support in knowledge management implementation.

In addition, knowledge management should never be viewed as a way to control the process of knowledge creation. In his book enabling knowledge creationGeorge Van Krogh et al made a strong argument for supporting knowledge creation rather than controlling it. In the process of knowledge creation, every library should strive to be an enabler and facilitator by mobilizing all its efforts and resources.

Academics are best knowledge creators. Knowledge creations is best performed by higher institutions of learning. As a learning and knowledge organisation, higher institution of learning should empower their libraries to develop campus wide knowledge management systems. It is now time for libraries to reposition themselves in the central stage of and as a leading player in knowledge management.

\section{References}

[1] Chem., H. (2001): knowledge Management system: A text mining perspectives. Tucson, Arisona, University of Arizona P. 18

[2] Cohen, S. et al (2004): 'Personalized Electronic services in the Cornell University Libraries" D-Lib magazine 6,No. 4:1-2. Arailable Online from http://www.dlib.org/dib/apriloo/mistlebauer/04mistle bauer.html

[3] Krogh, G. et al (2000): enabling Knowledge creation: how to unlock the Mystery of tacit knowledge and Release the power of innovation. New York: Oxford University Press.

[4] Lee, H. (2005): Knowledge management and the role of libraries. Available on line from Lee@ic.gov. 